\title{
Hematological and biochemical parameters of dairy calves submitted to pegbovigrastim administration
}

\author{
F. Kegles, ${ }^{1}$ O. C. Madruga, ${ }^{1}$ E. Schmoeller, ${ }^{1}$ L. F. Bragança, ${ }^{1}$ U. S. Londero, ${ }^{1}$ L. Marins, ${ }^{1}$ J. O. Feijó, ${ }^{1}$ \\ M. N. Corrêa, ${ }^{1,2}$ E. Schmitt, ${ }^{1,2}$ and F. A. B. Del Pino ${ }^{3 *}$ \\ ${ }^{1}$ Núcleo de Pesquisa, Ensino e Extensão em Pecuária, Livestock Research, Education and Extension Center, Universidade Federal de Pelotas, \\ CEP 96010-900, Capão do Leão, RS, Brazil \\ ${ }^{2}$ Departamento de Clínicas Veterinárias, Faculdade de Veterinária da Universidade Federal de Pelotas, CEP 96010-900, Capão do Leão, RS, \\ Brazil \\ ${ }^{3}$ Centro de Ciências Químicas Farmacêuticas e de Alimentos, Universidade Federal de Pelotas, CEP 96010-900, Capão do Leão, RS, Brazil
}

\section{ABSTRACT}

This study was designed to evaluate the response of hematological and biochemical parameters submitted to pegbovigrastim administration and postchallenge with lipopolysaccharide (LPS). In experiment 1, 20 newborn Holstein calves were divided into 2 groups: the Imrestor (Elanco Saúde Animal, São Paulo, Brazil) group (IMR, $\mathrm{n}=10$ ), which received a $25 \mu \mathrm{g} / \mathrm{kg}$ of body weight (BW) subcutaneous administration of pegbovigrastim, and the control group (CTR, $\mathrm{n}=10$ ), which received a subcutaneous administration of $0.9 \%$ saline solution. Blood samples were collected on d 0,10 , 12 , and 14 relative to birth to analyze the biochemical and hematological parameters. Moreover, growth measurements were taken on d $0,7,14,21$, and 60 relative to birth. The number of total leukocytes in the IMR group increased on d 12 and 14 in comparison to the CTR group, as well as the counts of segmented neutrophils, band cells, and monocytes. No differences were observed in the other hematological, biochemical, and growth parameters. In experiment 2, 20 Holstein calves from 30 to $60 \mathrm{~d}$ old were divided into 4 groups: group 1 (LPS, $\mathrm{n}=5$ ) received a $0.25 \mu \mathrm{g} / \mathrm{kg}$ of $\mathrm{BW}$ single intravenous dose of Escherichia coli LPS at d 0; group 2 (IMR, $\mathrm{n}=5$ ) received a $25 \mu \mathrm{g} / \mathrm{kg}$ of BW subcutaneous dose of pegbovigrastim at d 1 ; group 3 (IMR + LPS, $\mathrm{n}=5$ ) received a $0.25 \mu \mathrm{g} / \mathrm{kg}$ of BW intravenous LPS dose at $\mathrm{d} 0$ and a $25 \mu \mathrm{g} / \mathrm{kg}$ of BW subcutaneous dose of pegbovigrastim at d 1 ; and group $4(\mathrm{CTR}, \mathrm{n}=5)$ received an intravenous dose of $0.9 \%$ sodium chloride at d 0 and a subcutaneous dose of $0.9 \%$ sodium chloride at d 1. For the analysis of biochemical and hematological parameters, blood samples were collected on d $-1,0,1$,

Received January 14, 2018.

Accepted September 7, 2018.

*Corresponding author: fabdelpino@gmail.com
$2,3,4,8,14$, and 21 relative to LPS administration. An increase in the number of total leukocytes was observed in the IMR, IMR + LPS, and LPS groups, and the IMR group remained as the highest from d 2 to 21 . The levels of paraoxonase 1 were higher in the IMR group compared with all the others. The administration of pegbovigrastim in the dairy calves increased the number of circulating leukocytes, especially neutrophils, with an increase in paraoxonase 1, without altering the metabolites for the hepatic function.

Key words: dairy calf, lipopolysaccharide, pegbovigrastim

\section{INTRODUCTION}

The role of peripheral blood phagocytes in preventing infections is one of the most important nonspecific defense mechanisms of dairy calves. Neutrophils are the major immune cells that fight pathogens, and their production is regulated by granulocyte colony-stimulating factor (G-CSF), which induces differentiation from myeloblast to neutrophil, reduces maturation time in the bone marrow, and alters its functionality by increasing phagocytosis and cytotoxicity mediated by antibody-dependent cells and by starting oxidation (Mayadas et al., 2014; McDougall et al., 2017).

Recently, a bovine G-CSF was developed through covalent binding of polyethylene glycol (PEG) to GCSF to increase its lifespan around 7 to $14 \mathrm{~d}$ and allow a reduction in first-pass renal clearance and proteolytic degradation (Kehrli et al., 1991; Molineux, 2003). Bovine G-CSF has been shown to significantly increase neutrophil concentration and function in peripartum cows, increase production of milk, and reduce susceptibility to clinical mastitis during lactation (Canning et al., 2017; Ruiz et al., 2017). However, no information is available regarding the effectiveness of the response to PEG bovine G-CSF on calves' immune system and their metabolic profile. 
The high incidence of diarrhea in this bovine class has been associated with a great number of infectious agents, such as the Escherichia coli, which is one of the most prevalent. Lipopolysaccharide is a constituent of its outer membrane capable of eliciting an inflammatory response by increasing the production of proinflammatory cytokines (Crisan et al., 2016). Neutrophils have an important role in reducing these effects through the acyloxyacyl hydrolase. This key enzyme is responsible for detoxifying lipid A, which is a component of bacterial endotoxins and is also associated with most of its toxic effects (McDermott et al., 1991; McDermott and Fenwick, 1992). Also, Reber et al. (2017), studing the role of neutrophils in LPS-induced endotoxemia in a new mouse model that allows selective and inducible ablation of neutrophils, found that neutrophil myeloperoxidase enhances the innate host resistance to the toxic effects of LPS, once the group of mice with neutrophil depletion had an increased mortality and were more susceptible to endotoxemia at a 10 times reduced dose of LPS compared with the control group.

We proposed that subcutaneous administration of pegbovigrastim at $25 \mu \mathrm{g} / \mathrm{kg}$ of $\mathrm{BW}$ may reduce the negative effects on the liver function caused by an endotoxemia, which was mimicked by an LPS challenge in our study; also, it would not represent a metabolic challenge capable of impairing calves' health and growth. Thus, the aim of our study was to evaluate the short-term effects of the administration of PEG bovine G-CSF (pegbovigrastim) on circulating leukocyte counts and plasma biochemical markers, including the response to an inflammatory challenge with LPS.

\section{MATERIALS AND METHODS}

The experiments were approved by the Animal Ethics and Experimentation Committee of the Federal University of Pelotas (no. 9382). Two studies were conducted in 2 different commercial properties in the south of Rio Grande do Sul: $31^{\circ} 44^{\prime} \mathrm{S}, 52^{\circ} 28^{\prime} \mathrm{W}$ (experiment 1) and $32^{\circ} 16^{\prime} \mathrm{S}, 52^{\circ} 33^{\prime} \mathrm{W}$ (experiment 2 ). In both experiments, the immunostimulating PEG bovine G-CSF (pegbovigrastim, Imrestor, Elanco Saúde Animal, São Paulo, Brazil) was administered subcutaneously at a dose of $25 \mu \mathrm{g} / \mathrm{kg}$ of BW.

\section{Animals and Experimental Groups}

Experiment 1. Twenty newborn Holstein calves from a commercial farm were assigned to this experiment. The calves were housed in individual stalls, and only those with total plasma protein (TPP) levels above $5.5 \mathrm{~g} / \mathrm{dL}$ at 12 to $24 \mathrm{~h}$ after colostrum intake and without clinical changes until d 10 of life were considered for entry in the experiment. The animals received milk twice a day $(0800$ and $1600 \mathrm{~h})$, totaling $4 \mathrm{~L}$ per day, and water and concentrate were available ad libitum, being supplied at up to $3 \%$ of live weight, adjusted weekly according to NRC (2001).

The calves were randomly assigned into 2 groups: the Imrestor group (IMR, $\mathrm{n}=10)$, with an average birth weight $(\mathrm{kg})$ of $41.70 \pm 1.94$, which received a $25 \mu \mathrm{g} / \mathrm{kg}$ of BW s.c. administration of pegbovigrastim; and the control group (CTR, $\mathrm{n}=10$ ), with an average birth weight $(\mathrm{kg})$ of $42.05 \pm 1.94$, which received the placebo (0.9\% saline solution). Both administrations were performed at d 10 of life.

Experiment 2. Twenty Holstein calves aged between 30 and $60 \mathrm{~d}$ old from a commercial farm were assigned to this experiment. The animals were housed in individual stalls, and they were enrolled into 4 groups: group 1 (LPS, $\mathrm{n}=5$ ), which received a single intravenous dose of $0.25 \mu \mathrm{g} / \mathrm{kg}$ BW of Escherichia coli LPS (Sigma-Aldrich, St. Louis, MO) at d 0; group 2 (IMR, $\mathrm{n}=5$ ), which received a $25 \mu \mathrm{g} / \mathrm{kg}$ of BW s.c. dose of pegbovigrastim at d 1 ; group 3 (IMR + LPS, $\mathrm{n}=5$ ), which received a $0.25 \mu \mathrm{g} / \mathrm{kg}$ of BW LPS dose at $\mathrm{d} 0$ and a $25 \mu \mathrm{g} / \mathrm{kg}$ of BW pegbovigrastim dose at d 1; group $4(\mathrm{CTR}, \mathrm{n}=5)$, which received an i.v. placebo dose of $0.9 \% \mathrm{NaCl}$ at $\mathrm{d} 0$ and another subcutaneous dose of saline at $\mathrm{d} 1$. All the doses were calculated according to the animals' weights.

\section{Clinical Evaluations}

The animals were monitored daily, and in the case of clinical symptomatology manifestation, a clinical examination was performed. The main vital signs analyzed were heart rate through auscultation of the cardiac area; respiratory rate by pulmonary auscultation; body temperature, measured by insertion of a mercury thermometer into the rectal ampulla; mucous membrane color; and capillary refill time evaluated by compressing the oral mucosa, considering the physiological parameters proposed by Feitosa (2000).

\section{Blood Tests}

Blood samples were collected by jugular vein puncture using the vacutainer system (Vacuplast, Shandong, China). The samples were collected in 2 tubes: one containing EDTA to perform hematological analysis and another containing silicon (clot activator) to obtain serum and perform biochemical analyses.

In experiment 1 , the samples were taken at $0,10,12$, and $14 \mathrm{~d}$ of age. The samples of $\mathrm{d} 0$ were used only for 
the addition or exclusion of the animals, whereas, in experiment 2 , the samples were taken at $-1,0,1,2,3$, $4,8,14$, and $21 \mathrm{~d}$ relative to LPS administration.

After collection, the samples in the clot activator tube from both experiments were centrifuged (Centrifuge Sirius 4000, Sieger, Parana, Brazil) at 1,800 $\times g$ for $15 \mathrm{~min}$ at $24 \pm 3^{\circ} \mathrm{C}$ to obtain the serum. Samples were then transferred to Eppendorf tubes and stored at $-20^{\circ} \mathrm{C}$ for further analysis of albumin (ALB), aspartate aminotransferase (AST), creatinine (CREAT), gamma glutamyl transferase (GGT), TPP, and urea using commercial kits (Labtest Diagnostica SA, Minas Gerais, Brazil). In addition, the C-reactive protein (CRP) analysis was also performed in experiment 2. The samples analyses were performed by using an automatic biochemical analyzer Labmax Plenno (Labtest Diagnostica SA, Minas Gerais, Brazil). The globulin concentration was determined by subtracting the ALB from the TPP (Silva et al., 2008).

The analyses of the inflammatory parameters were performed at d 10, 12, and 14 in the first experiment and at $\mathrm{d} 0,2$, and 8 in the second experiment. The colorimetric method described by Jones and Mould (1984) and adapted by Schneider et al. (2013) was used to measure haptoglobin (HP) concentration, using a microplate reader (Thermo Plate TP-Reader, São Paulo, Brazil). Moreover, these samples were also used to analyze the serum activity of paraoxonase 1 (PON1) as the protocol described by Browne et al. (2007). The reading was performed using a UV-visible spectrophotometer (Femto, São Paulo, Brazil) with a wavelength of $270 \mathrm{~nm}$ and a reading time of $30 \mathrm{~s}$. The activity of the enzyme determined by the formula $\Delta$ absorbance $\times 115 \times 4$.

The d 0 samples from experiment 1 were submitted for centrifugation in digital microhematocrit (Benfer, São Paulo, Brazil) with 1.0-mm internal capillary tubes (Perfecta, São Paulo, Brazil) at 2,650 $\times g$ for 5 min at $24 \pm 3^{\circ} \mathrm{C}$. The serum of capillary tube was then read into the refractometer for TPP analysis (Atago, Tokyo, Japan). The other EDTA samples from this experiment were sent to a commercial laboratory to perform the blood count with erythrogram and leukogram evaluation.

To perform the hemogram of experiment 2, the red blood cell and white blood cell (WBC) counting was performed by an automatic cell counter, CC530 (CELM, São Paulo, Brazil) using the impedance method. Initially, the samples were diluted in the automatic diluent DA-500 (CELM) at ratios of 1:500 for WBC and 1:49,999 for red blood cells. The leukocyte cell differential was determined by counting 100 cells in blood smears stained with Panótico Rápido (Labor-
Clin, Paraná, Brazil) and read in an optical microscope (Nikon Eclipse E200, Nikon Instruments Inc., Tokyo, Japan) by a single evaluator.

The hematocrit of each sample from the second experiment was determined in duplicate using a digital microhematocrit centrifuge (Benfer, São Paulo, Brazil) with internal 1.0-mm capillary tubes (Perfecta, São Paulo, Brazil) subjected to $5 \mathrm{~min}$ of centrifugation at 2,650 $\times g$ and measured with a micro-hematocrit reader. After this analysis, one of the capillary tubes was used to determine TPP by refractometry (Atago), whereas the other was placed in a water bath (Quimis, São Paulo, Brazil) for 5 min at $56^{\circ} \mathrm{C}$, then centrifuged again in the same conditions for the determination of plasma fibrinogen using the method based on the precipitation of fibrinogen recommended by Jain and Jain (1993), and it was measured by refractometry.

The intra- and interassay coefficients of variation were, respectively, $1.82 \%$ and $4.76 \%$ for ALB, $3.18 \%$ and $5.33 \%$ for AST, $3.28 \%$ and $7.36 \%$ for CREA, $1.70 \%$ and $8.20 \%$ for GGT, $3.27 \%$ and $7.98 \%$ for urea, $1.95 \%$ and $5.23 \%$ for CRP, $1 \%$ and $3.14 \%$ for HP, $4.97 \%$ and $9.8 \%$ for PON1, and $2.23 \%$ and $4.93 \%$ for TPP. The maximum and minimum quantification limits of the assays were, respectively, 0.2 to $6 \mathrm{~g} / \mathrm{dL}$ for ALB, 3.5 to $400 \mathrm{U} / \mathrm{L}$ for AST, 0.2 to $12 \mathrm{mg} / \mathrm{dL}$ for CREAT, 2 to $700 \mathrm{U} / \mathrm{L}$ for GGT, 2 to $300 \mathrm{mg} / \mathrm{dL}$ for urea, 2 to 100 $\mathrm{mg} / \mathrm{dL}$ for CRP, 0.1 to $4 \mathrm{~g} / \mathrm{L}$ for HP, 10 to $200 \mathrm{U} / \mathrm{mL}$ for PON1, and 1 to $14 \mathrm{mg} / \mathrm{dL}$ for TPP.

\section{Growth Measurements}

Growth was evaluated through ADG and some body measurements at $\mathrm{d} 0,7,14,21$, and 60 in the first experiment. The weight was measured with a specific weight measuring tape for large dairy breeds (Bovitec, São Paulo, Brazil), whereas thoracic perimeter, wither height, and rump width were measured using a measuring tape.

\section{Statistical Analyses}

The sample sizes in both experiments were calculated a priori: computation required sample size power analyses test ( $\mathrm{G}^{*}$ Power 3.1.9.2 for Windows, 2010-2018 Heinrich-Heine-Universität Düsseldorf). In the both experiments the animals were grouped according to neutrophil count (d 10 and -1 in experiment 1 and 2, respectively). The dependent variables in both experiments were ALB, AST, CREAT, GGT, TPP, urea, CRP, globulin concentration, haptoglobin, serum activity of paraoxonase, blood cells, white blood cells, hematocrit, and plasma fibrinogen. In the first 
experiment the dependent variables weight, thoracic perimeter, wither height, and rump width were also included, which were measured using a measuring tape. The dependent variables were submitted for ShapiroWilk test $(P>0.90)$, and those considered with normal distribution had their means analyzed using ANOVA proc mixed models in the SAS statistical program (SAS Studio 3.5, SAS Institute Inc., Cary, NC). The model used was as follows: proc mixed method $=$ reml plots $=($ residualpanel $) \alpha=0.05$ covtest; class time group calf_id; dependent variable $=$ calf_id(group) time group time $\times$ group $/$ solution $\mathrm{cl} \alpha=0.05$ alphap $=0.05$ covb. The GLMM and Tukey-Kramer test was used to compare the main effects, and their interactions were included in the models and the $P$-values less than 0.05 were considered significant. The calf_id was a nested group, which was treated as a random effect.

The precision was evaluated by 6 analyses of the same sample at the same day (intraassay precision) and at different days (interassay precision). The precision calculus was expressed as a function of the coefficient of variation. The covariance structure selected was the variance component because it achieved the lowest Bayesian information criterion value of the studied variables.

\section{RESULTS}

\section{Experiment 1}

We observed an increase in the number of total leukocytes $(P<0.01$; Figure 1A) in the IMR group 48 $\mathrm{h}$ (d 12) after the administration of pegbovigrastim, and it remained high until $96 \mathrm{~h}$ (d 14) after treatment compared with the CTR group. At the same time, an increase in the segmented neutrophil count $(P<0.01$; Figure 1B), band cells $(P<0.01$; Figure $1 \mathrm{C})$, and monocytes $(P<0.01$; Figure 1D) was observed in the IMR group. No differences were observed in the other hematological and biochemical parameters analyzed $(P$ $>0.05$, Tables 1 and 2 , respectively).

When we analyzed the growth parameters, we observed no differences between the groups $(P>0.05$; Table 3$)$. The ADG $(P>0.05$; Figure 2$)$ differed only among the evaluated days; however, no differences were observed between groups $(P<0.01$, Table 3 ; Figure 2$)$.

\section{Experiment 2}

We observed an increase in the number of total leukocytes $(P<0.01$; Figure $3 \mathrm{~A})$ in the IMR, IMR + LPS, and LPS groups, and the IMR group remained with the highest number of cells $24 \mathrm{~h}$ after the administration of pegbovigrastim (d 2) up to $312 \mathrm{~h}$ after treatment (D14). The CTR group had lower levels of total leukocytes $(P>0.05$; Figure 3A); however, it remained stable at basal levels. The LPS group had a higher number of total leukocytes $(P<0.01$; Figure $3 \mathrm{~A}) 24 \mathrm{~h}$ after the administration of LPS (d 1), being higher than the other groups for this period. This pattern was observed in the same proportions by segmented neutrophils $(P<$ 0.01 ; Figure $3 \mathrm{~B})$ and to a lesser extent by lymphocytes $(P<0.01$; Figure 3D). For band cells $(P<0.01$; Figure $3 \mathrm{C})$, a significant increase of the IMR and IMR + LPS groups occurred $24 \mathrm{~h}$ after the administration of pegbovigrastim (d 2). No differences were observed among the groups for the other hematological parameters $(P$ $>0.05$; Table 4 ).

In the biochemical parameters, we observed that the IMR group maintained ALB levels equal to CTR, whereas the IMR + LPS group had smaller levels than the IMR group $(P<0.01)$ but equal to the CTR group. Moreover, PON1 levels were higher in the IMR group $(P=0.02)$ compared with all the others. As for the CRP levels, the CTR group differed from the LPS group obtaining lower concentrations $(P=0.03)$. For AST, the IMR group did not differ from the CTR group, and the IMR + LPS and LPS groups differed between themselves and from IMR and CTR $(P<0.01)$, whereas the IMR + LPS group had the lowest levels of this enzyme. Regarding GGT, we observed that the IMR + LPS group had the highest values $(P<0.01)$, differing from the other groups. For the levels of urea, the IMR + LPS group had the lowest values, differing from the IMR and CTR groups $(P=0.02)$. In addition, for CREAT, the IMR and LPS groups showed lower levels $(P=0.02)$, and the IMR group differed from the CTR and IMR + LPS groups but did not differ from the LPS group. The other metabolites analyzed (globulins, HP, and TPP, $P>0.05$, Table 5) showed no differences between the groups.

\section{DISCUSSION}

The number of total leukocytes and segmented neutrophils in experiment 1 was higher in the IMR group than in the CTR group, reaching a peak at $24 \mathrm{~h}$ (d 2) after the administration of pegbovigrastim and decreasing $48 \mathrm{~h}$ after (d 3), but nevertheless maintaining a neutrophilia up to $312 \mathrm{~h} \mathrm{(d} \mathrm{14)} \mathrm{after} \mathrm{treatment.} \mathrm{Similar}$ results were found in peripartum cows receiving pegbovigrastim $7 \mathrm{~d}$ before calving and $24 \mathrm{~h}$ postpartum, in which neutrophils remained elevated for at least 7 d after the second dose (Canning et al., 2017). These results could justify the use of this drug in newborn calves because it increases the number of circulating 
$\rightarrow$ CTR
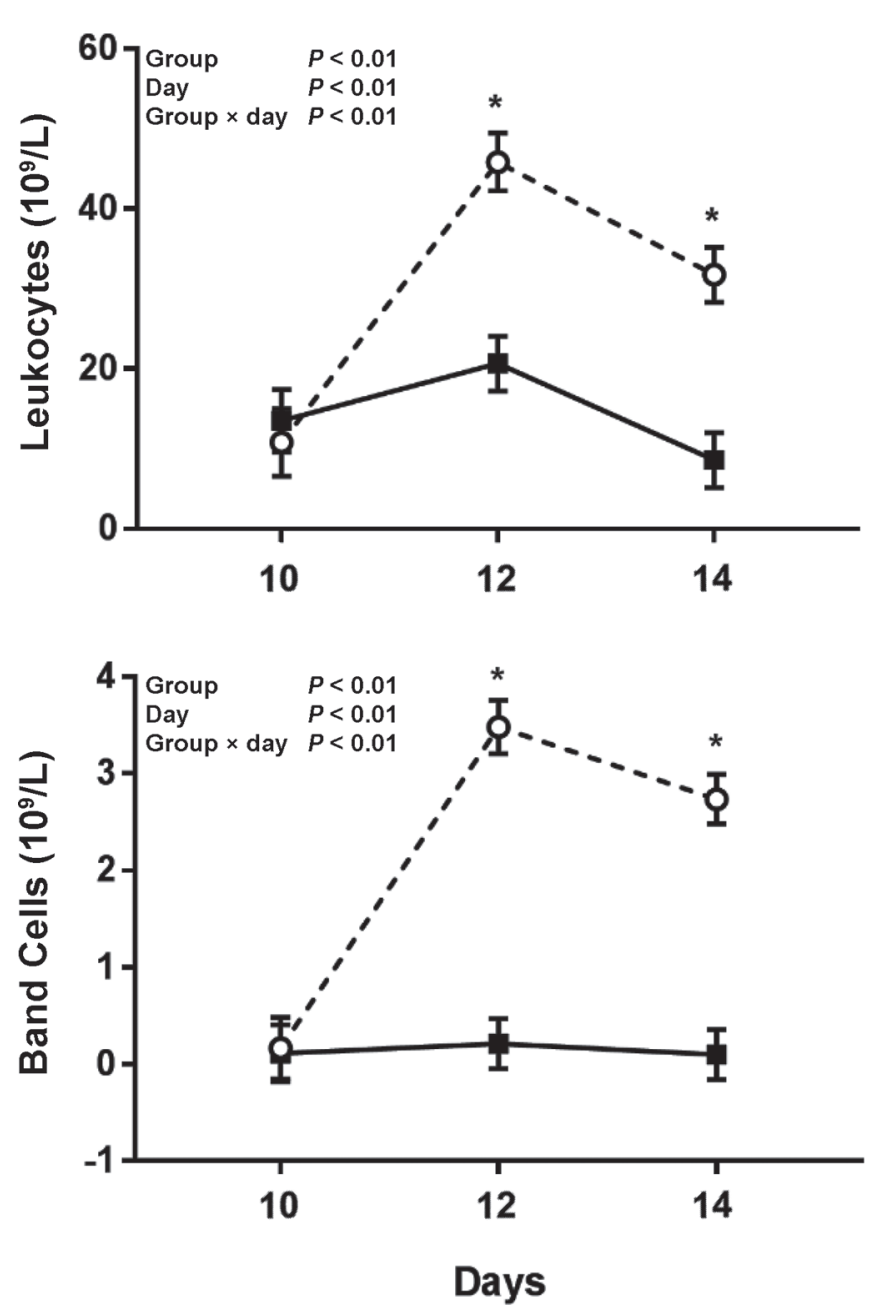

$-\Theta \cdot I M R$
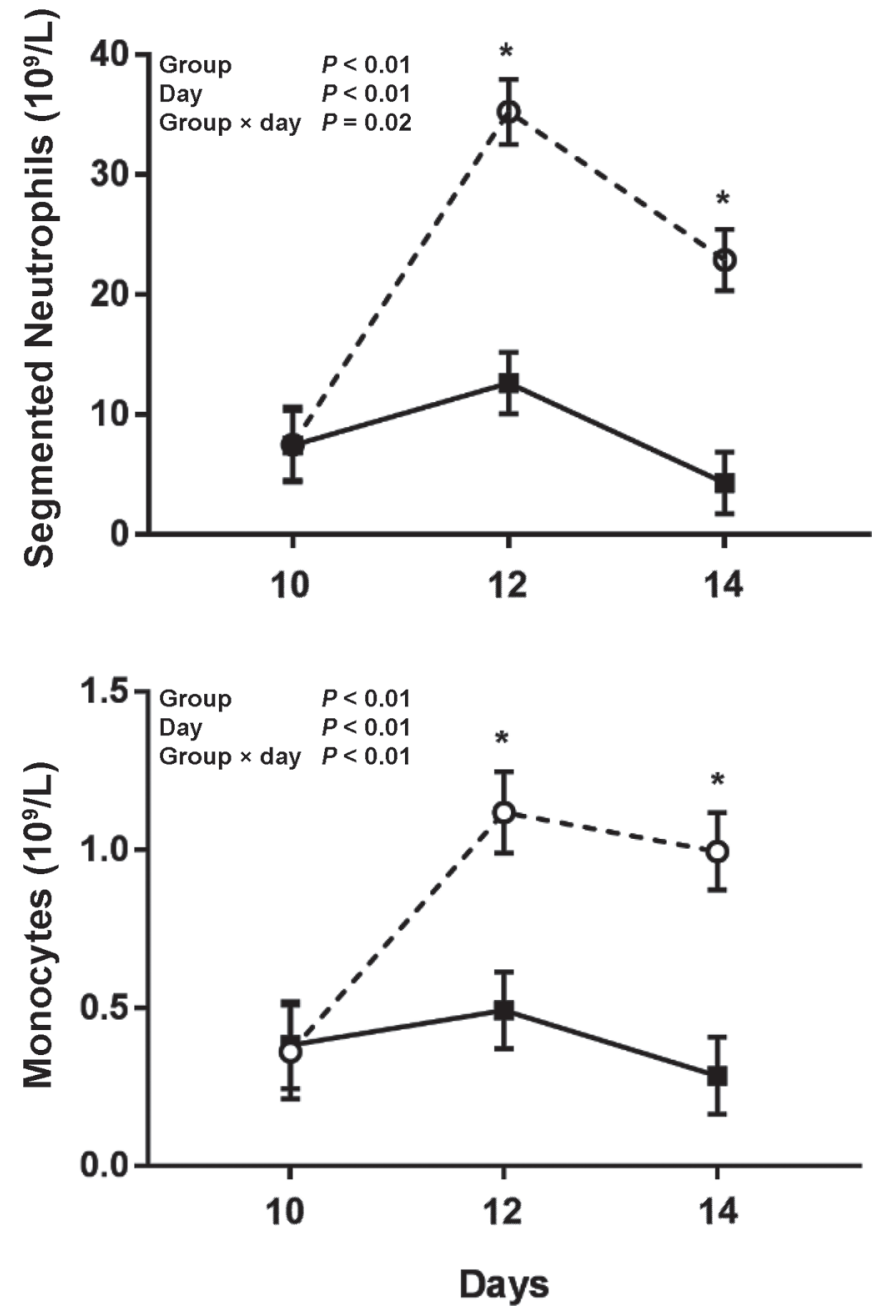

Figure 1. Mean \pm SE of leukocytes, segmented neutrophils, band cells, and monocytes of calves evaluated on the day of treatment administration (d 10), $48 \mathrm{~h}$ (d 12), and $96 \mathrm{~h}$ after (d 14), for the control (CTR) and Imrestor (IMR; Elanco Saúde Animal, São Paulo, Brazil) groups. *Differences between groups $(P<0.05)$.

Table 1. Mean $\pm \mathrm{SE}$ of hematological parameters of calves evaluated on the day of treatment administration (d 10), $48 \mathrm{~h}(\mathrm{~d} 12)$, and $96 \mathrm{~h}$ after (d 14), for the control (CTR) and Imrestor (IMR; Elanco Saúde Animal, São Paulo, Brazil) groups

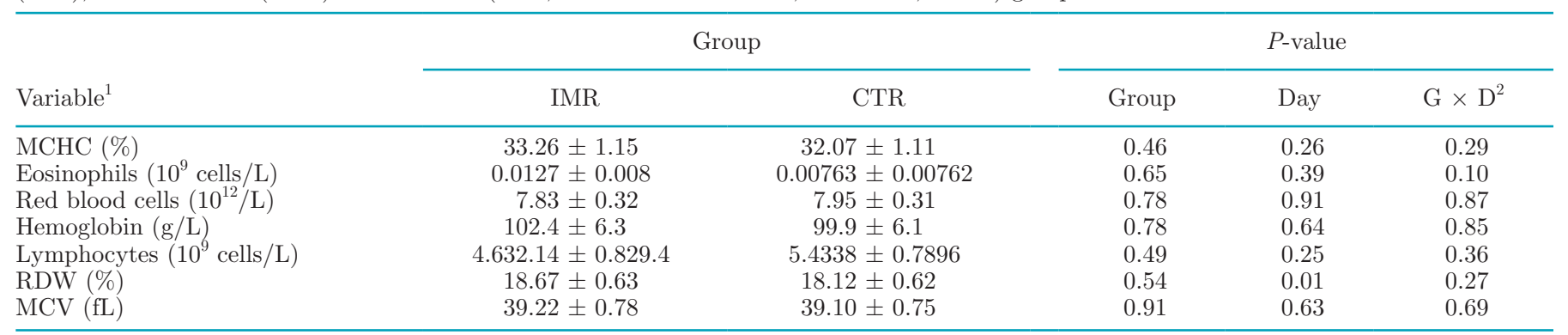

${ }^{1} \mathrm{MCHC}=$ mean corpuscular hemoglobin concentration; RDW $=$ red cell distribution width; $\mathrm{MCV}=$ mean corpuscular volume.

${ }^{2} \mathrm{G} \times \mathrm{D}=$ group by day interaction. 


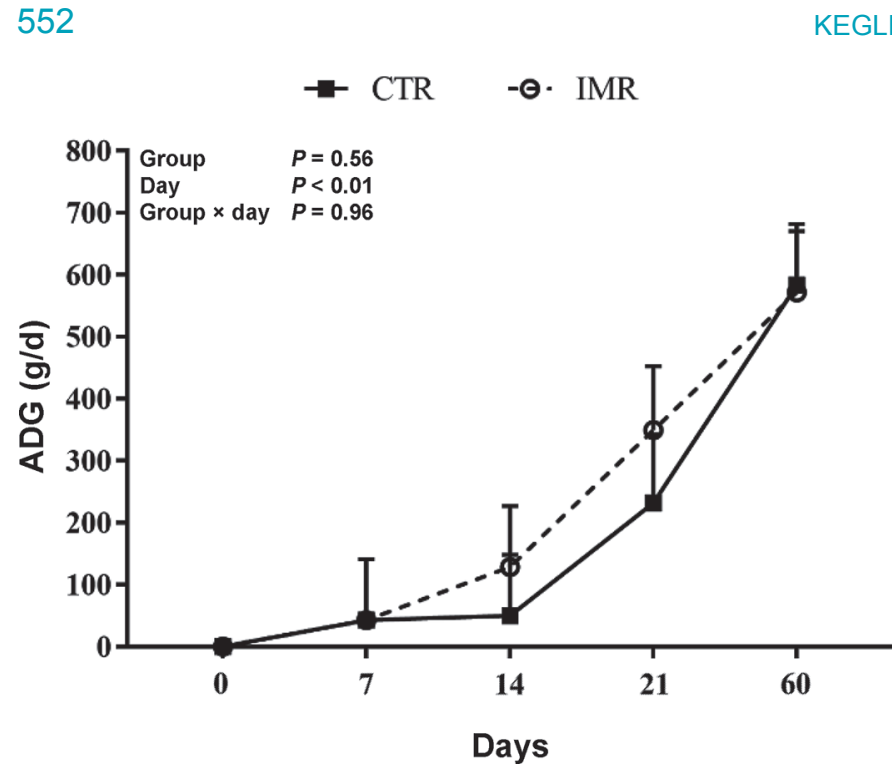

Figure 2. Mean $\pm \mathrm{SE}$ of the mean ADG of calves evaluated in the first $60 \mathrm{~d}$ of life, for the control (CTR) and Imrestor (IMR; Elanco Saúde Animal, São Paulo, Brazil) groups.

cells of innate immunity. In the early weeks of life, it could provide an advantage for some individuals during this crucial period, where the main challenges caused by pathogenic agents occur.

In the same way, in experiment 2 , both groups that received PEG had a higher number of total leukocytes and segmented neutrophils than the CTR group. However, the IMR + LPS had a lower peak than the IMR group. Other studies investigating the effects of LPS on the WBC found an LPS-time interaction with neutrophils, in which this leukocyte showed an increase at $12 \mathrm{~h}$ after LPS administration (Yates et al., 2011). The LPS exposition $24 \mathrm{~h}$ before PEG administration could have modulated the leucocyte recruitment, which could explain why the IMR + LPS group had a smaller peak of neutrophils than the IMR group. In rats, high levels of dietary LPS have been associated with the decrease of neutrophils in the lymphatic vessels, so another blood collection procedure a few hours after LPS injection and $24 \mathrm{~h}$ again to evaluate the response could be proposed (Chakraborty et al., 2013). Despite this, the PEG in the IMR + LPS group has shown to be able to maintain a significant effect on neutrophil recruitment, which could be considered a potential strategy to decrease the toxic effects of LPS. Recently, McDougall et al. (2017) showed that the PEG effects were not influenced by energetic status. In this sense, even in inadequate nutritional conditions, such as in a convalescent patient, PEG would be able to recruit the neutrophils, and its myeloperoxidase action could be maintained, reducing the LPS toxic effects (Reber et al., 2017).

Although the hematological PEG effects have been seen in adults, our study was proposed to evaluate the possible metabolic effects on the protein metabolism parameters because PEG induces a quick inflammatory cell release. In lactating cows, it was recently demonstrated that an acutely activated immune system uses $>1 \mathrm{~kg}$ of glucose within $720 \mathrm{~min}$ to respond to an LPS challenge (Kvidera et al., 2017). Based on this, we supposed that PEG and endotoxemia combined could stimulate an exacerbated metabolic response, and this would impair the hepatic function.

However, PEG administration did not significantly alter most of the parameters related to hepatic and protein metabolism in both experiments, showing that in these conditions, PEG administration was not a metabolic challenge to these animals. On the other hand, PON1 activity was lower in the animals of experiment 1 , which may be explained by the difference in the ani-

Table 2. Mean \pm SE of biochemical parameters of calves evaluated on the day of treatment administration (d 10), $48 \mathrm{~h}(\mathrm{~d} 12)$, and $96 \mathrm{~h}$ after (d 14), for the control (CTR) and Imrestor (IMR; Elanco Saúde Animal, São Paulo, Brazil) groups

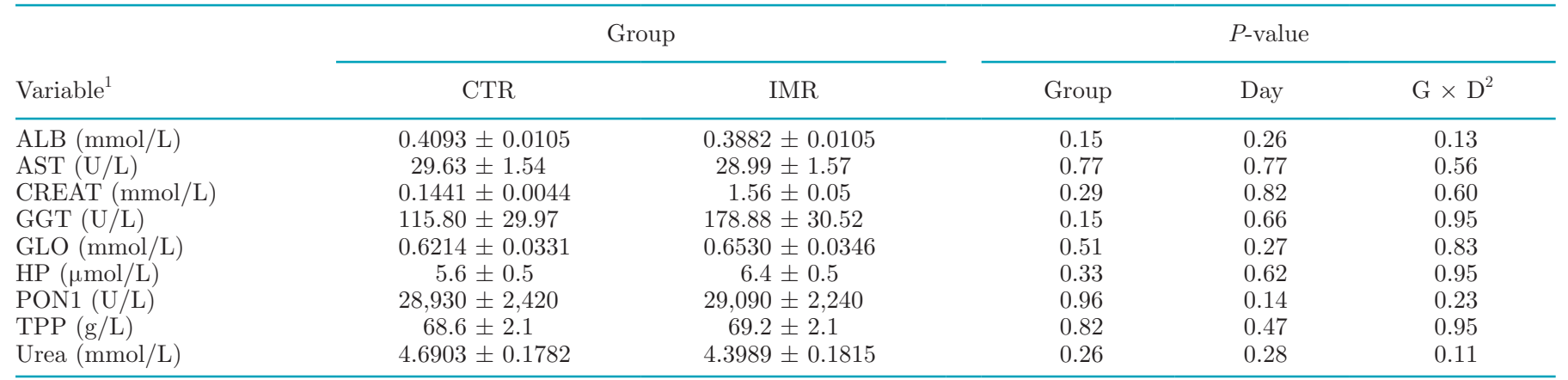

${ }^{1} \mathrm{ALB}=$ albumin; $\mathrm{AST}=$ aspartate aminotransferase; CREAT $=$ creatinine; GGT $=$ gamma glutamyl transferase; GLO $=$ globulins; HP $=$ haptoglobin; $\mathrm{PON} 1=$ paraoxonase $1 ; \mathrm{TPP}=$ total plasma proteins.

${ }^{2} \mathrm{G} \times \mathrm{D}=$ group by day interaction. 
Table 3. Mean $\pm \mathrm{SE}$ of the development of calves evaluated at d 0,7,14,21, and 60 in relation to birth, for the control (CTR) and Imrestor (IMR; Elanco Saúde Animal, São Paulo, Brazil) groups

\begin{tabular}{lcccccc}
\hline & \multicolumn{2}{c}{ Group } & & \multicolumn{3}{c}{$P$-value } \\
\cline { 2 - 3 } \cline { 6 - 8 } Variable & IMR & CTR & & Group & Day & $\mathrm{G} \times \mathrm{D}^{1}$ \\
\hline Height of withers (cm) & $80.11 \pm 0.41$ & $80.52 \pm 0.42$ & & 0.49 & $<0.01$ & 0.73 \\
Thoracic perimeter (cm) & $81.10 \pm 0.48$ & $81.42 \pm 0.48$ & & 0.64 & $<0.01$ & 0.99 \\
Width of rump (cm) & $21.38 \pm 0.17$ & $21.45 \pm 0.17$ & & 0.76 & $<0.01$ & 0.75 \\
\hline
\end{tabular}

${ }^{1} \mathrm{G} \times \mathrm{D}=$ group by day interaction.

mals' age in the experiments, which was around $40 \mathrm{~d}$ because it was already observed that PON1 activity is lower in newborns compared with adults (Sumegová et al., 2007). Moreover, we observed that in experiment 2, the IMR group had higher PON1 activity, which could suggest that in addition to the increased number of

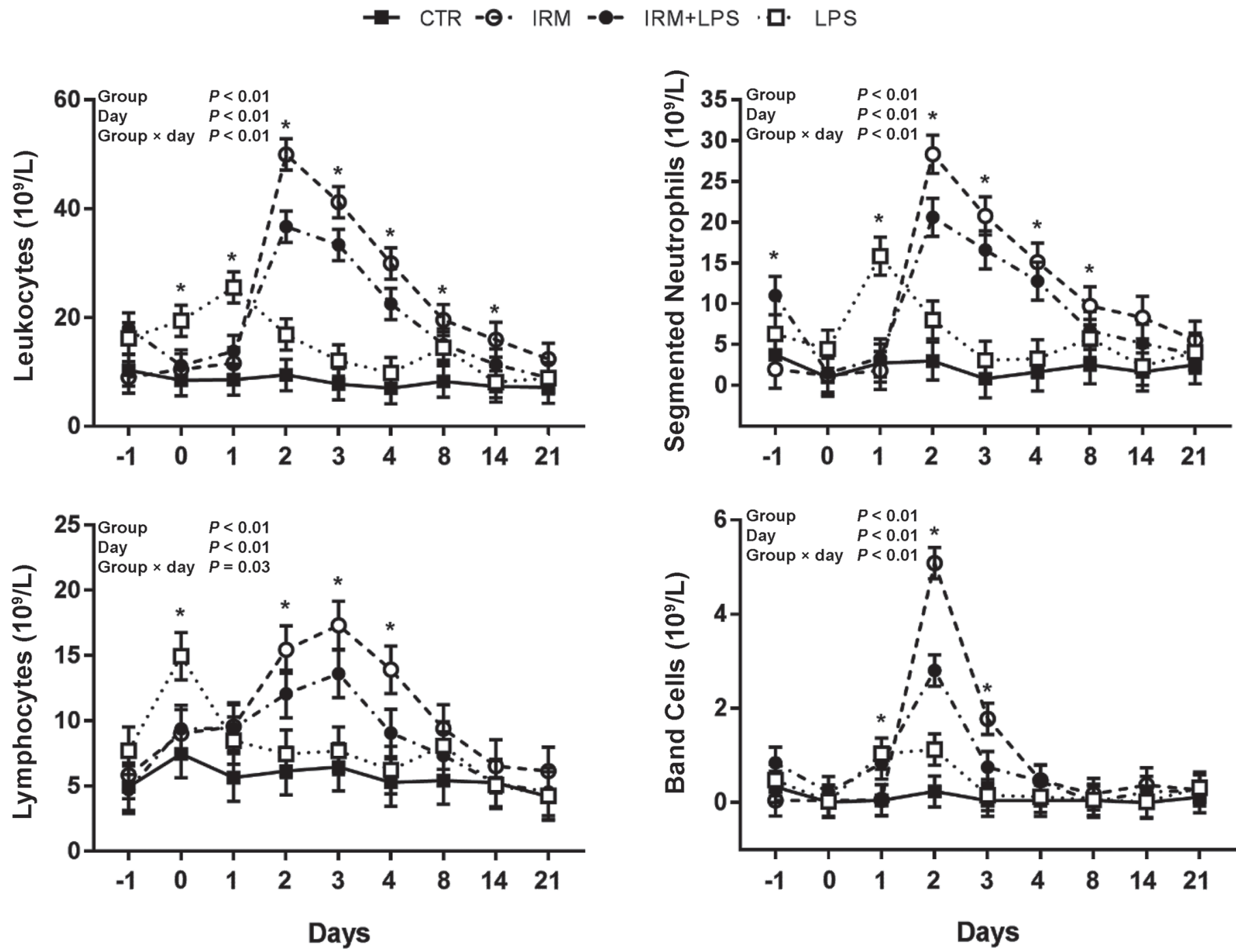

Figure 3. Mean \pm SE of leukocytes, segmented neutrophils, band cells, and lymphocytes evaluated $1 \mathrm{~d}$ before administration of LPS (d -1 ), on the day of LPS administration (d 0), $24 \mathrm{~h}$ (administration of pegbovigrastim, d 1), $48 \mathrm{~h} \mathrm{(d} \mathrm{2),72} \mathrm{h} \mathrm{(d} \mathrm{3),} \mathrm{96} \mathrm{h} \mathrm{(d} \mathrm{4),} 192 \mathrm{~h}(\mathrm{~d} 8), 336 \mathrm{~h}$ (d 14), and $504 \mathrm{~h}$ after (d 21), for the control (CTR), Imrestor (IMR; Elanco Saúde Animal, São Paulo, Brazil), IMR + LPS, and LPS groups. *Differences between groups $(P<0.05)$. 

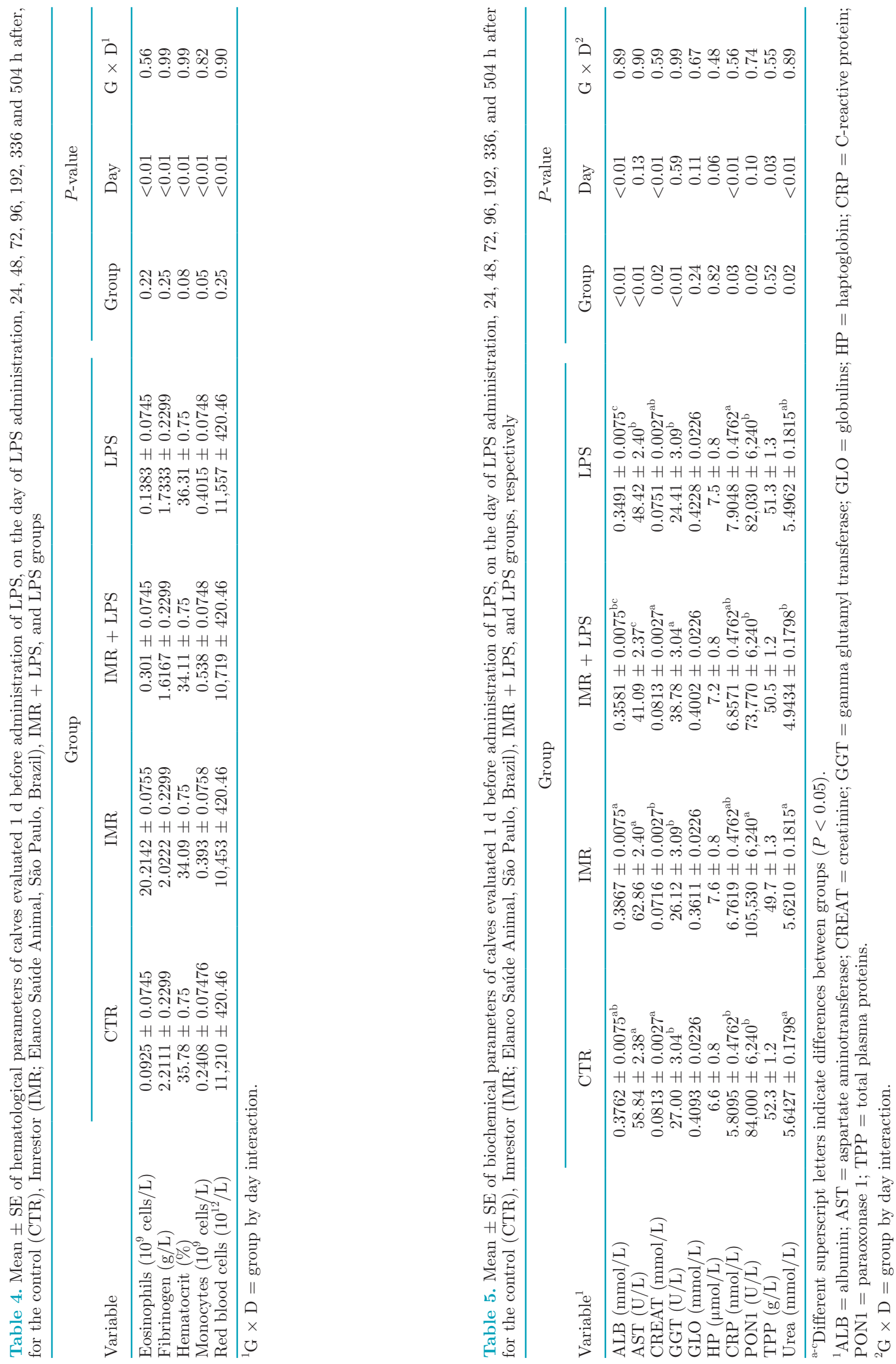
defense cells, this drug could help increase antioxidant proteins and then reduce the damage of inflammatory processes generated by reactive oxygen species. Nevertheless, this effect was not evidenced in the IMR + LPS group.

Although higher GGT levels in the IMR + LPS group were observed, which could indicate a metabolic challenge, the values of GGT for all groups were maintained among the reference values for this category (Trefz et al., 2017). Nonetheless, the GGT activity could have been influenced by colostrum ingestion until approximately $40 \mathrm{~d}$ of age (Knowles et al., 2000).

In experiment 1 , we recorded the withers height, thoracic perimeter, rump width, and ADG to evaluate the growth of the animals (Frenau et al., 2007). The treatment did not have a significant effect on the growth parameters analyzed. Apparently, PEG administration did not impair the energetic balance of the calves, although additional studies should be conducted to study this effect. As described by Ingvartsen and Moyes (2013), an exacerbated neutrophil recruitment requires a fairly amount of energy, thus PEG administration could represent a high energy cost; however, our results suggest that PEG treatment do not impair the energetic balance of newborn calves.

\section{CONCLUSIONS}

The results of this study showed that PEG administration in dairy calves increased the number of circulating leukocytes, especially segmented neutrophils, even when the calves were challenged with LPS. An increase in PON1 was also observed but did not alter the fundamental parameters of hepatic function. These results suggest that PEG could be used to elevate immune status in dairy calves, which could improve their response to infectious agents.

\section{ACKNOWLEDGMENTS}

The authors are grateful to the Funding Officer for Studies and Projects (FINEP, Rio de Janeiro, Brazil), the Coordination for the Improvement of Higher Education Personnel (CAPES, Brasilia, Brazil), the National Council for Scientific and Technological Development (CNPq, Brasilia, Brazil) and the Foundation for Research Support of the State of Rio Grande do Sul (FAPERGS, Porto Alegre, Brazil), and Resolpec Cooperation (Prado, Brazil) for the financial support, and the commercial properties Fazenda Leite Sul (Capão do Leão, Brazil) and Granjas 4 Irmãos (Rio Grande, Brazil) for the availability of the animals and the partnership formed.

\section{REFERENCES}

Browne, R. W., S. T. Koury, S. Marion, G. Wilding, P. Muti, and M. Trevisan. 2007. Accuracy and biological variation of human serum paraoxonase 1 activity and polymorphism (Q192R) by kinetic enzyme assay. Clin. Chem. 53:310-317.

Canning, P., R. Hassfurther, T. TerHune, K. Rogers, S. Abbott, and D. Kolb. 2017. Efficacy and clinical safety of pegbovigrastim for preventing naturally occurring clinical mastitis in periparturient primiparous and multiparous cows on US commercial dairies. J. Dairy Sci. 100:6504-6515.

Chakraborty, S., D. C. Zawieja, and M. Muthuchamy. 2013. LPS mediated decreases in immune cells recruitment on or near lymphatics impairs lymphatic contractility. FASEB J. 27:681.5.

Crisan, T. O., M. C. Cleophas, M. Oosting, H. Lemmers, H. ToenhakeDijkstra, M. G. Netea, T. L. Jansen, and L. A. Joosten. 2016. Soluble uric acid primes TLR-induced proinflammatory cytokine production by human primary cells via inhibition of IL-1Ra. Ann. Rheum. Dis. 75:755-762.

Feitosa, F. L. F. 2000. Semiologia Veterinária: A Arte Do Diagnóstico. Grupo Gen-Editora Roca Ltda., São Paulo, Brazil.

Frenau, G. E., J. C. Cardoso da Silva, A. de Los Reys Borjas, and C. Amorim. 2007. Estudo de medidas corporais, peso vivo e condições corporal de fêmeas da raça nelore Bos taurus indicus ao longo de doze meses. Ciência Animal Brasileira 9:76-85.

Ingvartsen, K. L., and K. Moyes. 2013. Nutrition, immune function and health of dairy cattle. Animal 7(Suppl. 1):112-122. https:// doi.org/10.1017/S175173111200170X.

Jain, N. C., and A. Jain. 1993. Essentials of Veterinary Hematology. No. 04; SF769. 5, J3. Lea \& Febiger, Philadelphia, PA.

Jones, G., and D. Mould. 1984. Adaptation of the guaiacol (peroxidase) test for haptoglobins to a microtitration plate system. Res. Vet. Sci. 37:87-92.

Kehrli, M. E., J. S. Cullor, and S. C. Nickerson. 1991. Immunobiology of hematopoietic colony-stimulating factors: Potential application to disease prevention in the bovine. J. Dairy Sci. 74:4399-4412.

Knowles, T. G., J. E. Edwards, K. J. Bazeley, S. N. Brown, A. Butterworth, and P. D. Warriss. 2000. Changes in the blood biochemical and haematological profile of neonatal calves with age. Vet. Rec. 147:593.

Kvidera, S. K., E. A. Horst, M. Abuajamieh, E. J. Mayorga, M. V. Sanz Fernandez, and L. H. Baumgard. 2017. Glucose requirements of an activated immune system in lactating Holstein cows. J. Dairy Sci. 100:2360-2374. https://doi.org/10.3168/jds.2016-12001.

Mayadas, T. N., X. Cullere, and C. A. Lowell. 2014. The multifaceted functions of neutrophils. Annu. Rev. Pathol. 9:181-218.

McDermott, C., and B. Fenwick. 1992. Neutrophil activation associated with increased neutrophil acyloxyacyl hydrolase activity during inflammation in cattle. Am. J. Vet. Res. 53:803-807.

McDermott, C. M., J. S. Cullor, and B. W. Fenwick. 1991. Intracellular and extracellular enzymatic deacylation of bacterial endotoxin during localized inflammation induced by Escherichia coli. Infect. Immun. 59:478-485.

McDougall, S., S. LeBlanc, and A. Heiser. 2017. Effect of prepartum energy balance on neutrophil function following pegbovigrastim treatment in periparturient cows. J. Dairy Sci. 100:7478-7492.

Molineux, G. 2003. Pegylation: Engineering improved biopharmaceuticals for oncology. Pharmacotherapy 23:3S-8S. https://doi.org/10 $.1592 /$ phco.23.9.3S.32886.

NRC. 2001. Nutrient Requirements of Dairy Cattle. 7th ed. Natl. Acad. Press, Washington, DC.

Reber, L. L., C. M. Gillis, P. Starkl, F. Jönsson, R. Sibilano, T. Marichal, N. Gaudenzio, M. Bérard, S. Rogalla, C. H. Contag, P. Bruhns, and S. J. Galli. 2017. Neutrophil myeloperoxidase diminishes the toxic effects and mortality induced by lipopolysaccharide. J. Exp. Med. 214:1249-1258. https://doi.org/10.1084/jem 20161238 .

Ruiz, R., L. Tedeschi, and A. Sepúlveda. 2017. Investigation of the effect of pegbovigrastim on some periparturient immune disorders and performance in Mexican dairy herds. J. Dairy Sci. 100:33053317 . 
Schneider, A., M. Corrêa, and W. Butler. 2013. Acute phase proteins in Holstein cows diagnosed with uterine infection. Res. Vet. Sci. 95:269-271.

Silva, E. B. D., M. C. Soares Fioravanti, L. A. Franco da Silva, E. Gonçalves de Araújo, L. Borges de Menezes, M. Pacheco Miguel, and D. Vieira. 2008. Característica leucocitária, relação albumina/ globulina, proteína plasmática e fibrinogênio de bovinos da raça Nelore, confinados e terminados a pasto. Cienc. Rural 38:21912196.

Sumegová, K., Z. Nagyova, I. Waczulikova, I. Zitnanova, and Z. Durackova. 2007. Activity of paraoxonase 1 and lipid profile in healthy children. Physiol. Res. 56:351-357.
Trefz, F. M., I. Lorenz, A. Lorch, and P. D. Constable. 2017. Clinical signs, profound acidemia, hypoglycemia, and hypernatremia are predictive of mortality in 1,400 critically ill neonatal calves with diarrhea. PLoS One 12:e0182938. https://doi.org/10.1371/journal .pone.0182938.

Yates, D. T., C. A. Löest, T. T. Ross, D. M. Hallford, B. H. Carter, and S. W. Limesand. 2011. Effects of bacterial lipopolysaccharide injection on white blood cell counts, hematological variables, and serum glucose, insulin, and cortisol concentrations in ewes fed lowor high-protein diets. J. Anim. Sci. 89:4286-4293. https://doi.org/ 10.2527/jas.2011-3969. 